\title{
Achieving High Value Utilization of Bio-oil from Lignin Targeting for Advanced Lubrication
}

\author{
Liwen $\mathrm{Mu},{ }^{1}$ Yuguo Dong, ${ }^{2}$ Licheng $\mathrm{Li},{ }^{2, *}$ Xiaoli Gu${ }^{2, *}$ and Yijun Shi ${ }^{1, *}$
}

\begin{abstract}
High-value utilization of biomass has been driven by increasingly growing industrial demands. Herein, we offer a strategy composed of depolymerization and esterification reaction of lignin to transfer to bio-oil with high liquid yield (79.75 85.25\%), which is demonstrated as a high performance lubricant. Overall, the bio-oil has the excellent lubrication properties, where a significant wear reduction of $97.6 \%$ was observed as compared with polyethylene glycol 200. Meanwhile, the more ether and less acid in bio-oil could improve the anti-wear properties. This work provides a new application of utilizing lignin in advanced lubrication systems.
\end{abstract}

Keywords: Lignin; High-value; Lubrication; Bio-oil.

Received: 14 December 2020; Accepted date: 15 January 2021.

Article type: Research article.

\section{Introduction}

The development of alternative liquid fuels (bio-oil) from lignin has become the focus of much research recently and a frontier fossil-free topic in the new global energy area with good recycling economics. ${ }^{[1]}$ However, utilization of bio-oil in transportation fuel applications faces some difficult challenges when comparing to petroleum. Bio-oil is a poor fuel, which has high amounts of water $(20 \sim 30 \mathrm{wt} \%)$ and many highly oxygenated (up to $40 \mathrm{wt} \%$ ) products. ${ }^{[2-4]}$ As such, bio-oil upgrading is required to improve its energy density, which will inevitably lead to high cost, making it a non-economically viable alternative of traditional fossil fuels. Another challenge is the complex nature of bio-oil containing a vast variety of compounds of different molecular weights. ${ }^{[5]}$ Currently, there are no efficient methods to separate the compounds from bio-oil. In addition, it has been found that crude bio-oil has more unstable and corrosive properties as compared with traditional fossil oil, which leads to short machine service life and metal corrosion. ${ }^{[6]}$ These economic and technical barriers make the transportation fuel application of bio-oil not feasible to industrialize within a relatively short space of time.

Lubricant shows much better profit margins as the price

${ }^{1}$ Division of Machine Elements, Lulea University of Technology,

Luleå, 97187, Sweden

${ }^{2}$ College of Chemical Engineering, Nanjing Forestry University,

Nanjing 210037, China

*Email: lilc@njfu.edu.cn (L. Li), guxiaoli@njfu.edu.cn (X. Gu), yijun.shi@ltu.se (Y. Shi). of lubricant is about 10 times higher than that of transportation fuels (e.g. gasoline, diesel). The high water and oxygen content of bio-oil are not causing problems in many lubricants applications as oil-water emulsions are widely used as lubricants. Moreover, as the lubricants base fluids normally are mixtures of alkanes with different molecular weight, the complex nature of bio-oil will not pose a problem either. Hence, it is promising to use bio-oil as lubricants base oil after some easy molecular structure regulation to remove some harmful materials, e.g. easily evaporated components, corrosive compounds, etc.

Lubricants have been widely used in the modern times with the purpose of "durability" and "energy efficiency". ${ }^{[7]}$ The lubrication performance of lubricant could be governed by the affinity and mechanical properties of the lubricant, which could be affected by several factors. ${ }^{[8,9]}$ For example, the hydrogen bonding (H-bonding) among the functional group of lubricant seems to be an effective approach to improve the lubrication performance. ${ }^{[10]}$ It is very important to tailor the molecular structure of the bio-oil based lubricant from lignin for the lubricant application. However, current research about the liquefaction for lignin is mainly towards the fuel application without the consideration of the structure required in the lubricant application. Hence, the molecular structure regulation of bio-oil from the lignocellulose towards excellent lubricants is necessary to be conducted via the depolymerization and upgrading methods.

A first, auspicious and complementary valorization opportunity for the bio-oil is to depolymerize the lignin to 
low molecular weight chemicals. For example, Prof. Sels group has developed an integrated biorefinery that converts $78 \mathrm{wt} \%$ of birch wood into xylo-chemicals. ${ }^{[11]}$ Lewis acids/choline cloride/glycerol deep eutectic solvents were used for the efficient pretreatment of hybrid Pennisetum energy grass to produce antioxidative lignin. ${ }^{[12]}$ The reductive catalytic fractionation (RCF) method could be utilized to depolymerize the biomass feedstocks into phenolic monomers with high yields $(\sim 40 \mathrm{wt} \%$ based on total lignin).[13] Lignin depolymerization faces great challenges due its highly complex polymeric structure. Lignin is a polymer with three basic phenylpropane monomers, which are linked together by ether and C-C bonds. ${ }^{[14,15]}$ The $\beta-O-4$ ether bond in lignin is most easily cleaved, which are frequently used as the primary target of lignin depolymerization methods. ${ }^{[16]}$ In addition, there is some volatile or corrosive fatty acid (such as acetic acid) production during the depolymerization processes, which leads to instability of bio-oil.[17] The acid-catalyzed esterification between fatty acid and alcohol could be an alternative upgrading strategy to enhance the stability of the bio-oil. Normally, the ester shows good lubrication properties due to its stability and adhesion on the metal surface. Acid catalyst could be used in hydrolytic cleavage of $\beta-O-4$ ether bond and esterification reaction between fatty acid. ${ }^{[18]}$ Therefore, a depolymerization and esterification system needs to be designed for the bio-oil from lignin towards to high performance lubricant.

Herein, we propose the strategy in which the lignin is transferred into the high performance lubricant via the solid acid catalyst. As an example, a route to produce the bio-oil based lubricant by the integrated depolymerization and esterification method of lignin in the glycerol/methanol solvent mixture was developed. The various liquid yields are obtained at the different temperatures and catalyst loading conditions. The functional groups and components of bio-oil and thus its effect on the lubricating properties were investigated.

\section{Experimental section}

\subsection{Materials}

Titanium tetrachloride $\left(\mathrm{TiCl}_{4}\right)$, ammonia $\left(\mathrm{NH}_{3} \cdot \mathrm{H}_{2} \mathrm{O}\right.$, $\geq 99.95 \%$ ) were purchased from Shanghai Lingfeng Chemical Reagent Co., Ltd. Sodium lignosulfonate was purchased from TCI (shanghai). Methanol ( $\geq 99.5 \%)$, glycerol $(\geq 99 \%$, ethyl acetate $(\geq 99.5 \%)$, anhydrous sodium sulphate $(\geq 99 \%)$, sulfuric acid $\left(\mathrm{H}_{2} \mathrm{SO}_{4}, 95.0 \sim 98.0 \%\right)$ and hydroquinone $(\geq 99 \%)$ were purchased at Nanjing Chemical Reagent Co., Ltd. Poly(ethylene glycol) 200 was purchased from Sigma Aldrich. All materials were used as received without further treatment.

\subsection{Preparation of $\mathrm{SO}_{4}{ }^{2-} / \mathrm{TiO}_{2}$ catalyst}

$\mathrm{SO}_{4}{ }^{2-} / \mathrm{TiO}_{2}$ catalyst was prepared using two main steps, $\mathrm{TiO}_{2}$ synthesis and acidification. Specifically, $\mathrm{TiCl}_{4}$ aqueous mixture was prepared by adding $\mathrm{TiCl}_{4}$ into $0{ }^{\circ} \mathrm{C}$ deionized water with stirring. The volume ratio of $\mathrm{TiCl}_{4}$ to deionized water was kept below $1 / 100$. Then, diluted aqueous ammonia (ca. 5 8\%) was added into the above mixture until a final $\mathrm{pH}$ $=9$. Hydrous $\mathrm{Ti}(\mathrm{OH})_{4}$ was gradually precipitated from mixture and then washed with deionized water to require no $\mathrm{Cl}^{-}$ion in the last-patch water (detected by $0.1 \mathrm{M} \mathrm{AgNO}_{3}$ aqueous solution). The resulting solid was dried at $120^{\circ} \mathrm{C}$ for $12 \mathrm{~h}$ and calcined in a muffle furnace at $500{ }^{\circ} \mathrm{C}$ for $2 \mathrm{~h}$, which was transformed into mesoporous $\mathrm{TiO}_{2}$. Secondly, the acidification of $\mathrm{TiO}_{2}$ powders was carried out by impregnation of $1 \mathrm{M} \mathrm{H}_{2} \mathrm{SO}_{4}$ aqueous solution. The liquid to solid ratio was controlled at $0.31 \mathrm{~mL} / \mathrm{g}$ to achieve about 3 $\mathrm{wt} \%$ of sulfate content in final catalyst. Then, the mixture was dried at $120{ }^{\circ} \mathrm{C}$ for $12 \mathrm{~h}$ and calcined at $500{ }^{\circ} \mathrm{C}$ for $2 \mathrm{~h}$ under air atmosphere to obtain the $\mathrm{SO}_{4}^{2-} / \mathrm{TiO}_{2}$ catalyst.

\subsection{Preparation of bio-oil}

The $4 \mathrm{~g}$ sodium lignosulfonate, $30 \mathrm{~g}$ methanol/glycerol mixture $(4: 1 \sim 1: 1)$ and $\mathrm{SO}_{4}^{2-} / \mathrm{TiO}_{2}$ catalyst $(2.5 \sim 10.0 \mathrm{wt} \%$ based sodium lignosulfonate) were added to the hydrothermal reactor. Then, the mixture was heated from room temperature to $160 \sim 180{ }^{\circ} \mathrm{C}$ in an oven and kept at $160 \sim 180{ }^{\circ} \mathrm{C}$ for 1 hour. After that, the mixture was cooled down to room temperature in the air atmosphere and mixed with $0.03 \mathrm{~g}$ hydroquinone. The liquid solution was obtained after the filtration of the mixture. During the preparation process, the depolymerization reaction of the lignin via the hydrolytic cleavage of $\beta-\mathrm{O}-4$ ether bond will produce some relatively low molecular lignin and some kinds of small molecules such as acetic acid. In addition, there is the esterification reaction between fatty acid produced via the depolymerization reaction such as acetic acid and polyols such as glycerol via the solid acid catalyst, which will lead to the better lubrication properties and improve the anticorrosive properties of the lubricant. These will be confirmed in some following characterization of the bio-oil. The methanol in liquid solution was removed using a rotary evaporator at $30{ }^{\circ} \mathrm{C}$. The crude bio-oil without methanol was used to calculate the liquefaction yield based on Equation (1). Then, it was separated into organic bio-oil and aqueous fractions (glycerol/water) using ethyl acetate (DCM)/water(1:1 volume ratio) solution. Some anhydrous sodium sulfate was added in the DCM extracted oil fraction (bio-oil) to reduce the water and separated via the filtration method. The DCM in bio-oil was removed in a rotary evaporator at $45^{\circ} \mathrm{C}$. The bio-oil after the evaporation will be used as the lubricant. The lubricating oil yield was obtained from Equation (3).

The bio-oil was obtained from the lignin using the methanol-glycerol mixture and $\mathrm{SO}_{4}{ }^{2-} / \mathrm{TiO}_{2}$ catalyst at $160 \sim 180{ }^{\circ} \mathrm{C}$, which is lower than that in the traditional liquefaction method. We select three samples to investigate the chemical structure and lubrication properties of bio-oil. The differences among the three kinds of bio-oil are the 
reaction temperature and catalyst ratio. Specially, Bio-1 is obtained at $160{ }^{\circ} \mathrm{C}$ and $2.5 \%$ catalyst (based lignin); Bio-2 is synthesized at $160{ }^{\circ} \mathrm{C}$ and $5 \%$ catalyst; Bio-3 is obtained at $180{ }^{\circ} \mathrm{C}$ and $5 \%$

catalyst.

Liquefaction yield $=\left(\frac{\text { Liquid amount }- \text { glycerol amount }}{\text { Amount of sodium lignosulfonate }}\right)$ $\times 100 \%$

$$
\begin{gathered}
\text { Char yield }=\left(\frac{\text { Residue amount }}{\text { Amount of sodium lignosulfonate }}\right) \\
\times 100 \% \\
\text { Lubricating oil yield }=\left(\frac{\text { Amount of bio- } \text { oil }}{\text { Amount of sodium lignosulfonate }}\right) \\
\times 100 \%
\end{gathered}
$$

\subsection{Characterization}

$\mathrm{X}$-ray diffraction (XRD) of the $\mathrm{SO}_{4}{ }^{2-} / \mathrm{TiO}_{2}$ was analyzed on a Bruker $\mathrm{D} 8$ diffractometer equipped with a $\mathrm{Cu} \mathrm{K} \alpha$ radiation $(\lambda$ $=1.5406 \AA$ ). The $2 \theta$ value of diffractogram was recorded from $5^{\circ}$ to $60^{\circ}$ at a rate of $0.2 \mathrm{~s} / \mathrm{step}$. Fourier transform infrared spectroscopy (FT-IR) was performed on the Nicolet6700 spectrometer ( $\mathrm{KBr}$ pellets) in the wavenumber range of $2000 \mathrm{~cm}^{-1} \sim 400 \mathrm{~cm}^{-1}$ with a resolution of $4 \mathrm{~cm}^{-1}$. Nitrogen adsorption/desorption at $-196{ }^{\circ} \mathrm{C}$ was carried out using a Micromeritics ASAP2020. Surface area and pore volume of sample were calculated by Brunauer-Emmett-Teller (BET) method and by nitrogen adsorption at a relative pressure of 0.99 , respectively. Pore size distribution was obtained from adsorption branch by Barrett-Joyner-Halenda (BJH) method. The morphology of $\mathrm{SO}_{4}{ }^{2-} / \mathrm{TiO}_{2}$ was studied by a JEM-7600F Scanning electron microscopy (SEM). The acidic characteristic of $\mathrm{SO}_{4}{ }^{2-} / \mathrm{TiO}_{2}$ was determined by pyridine absorption infrared (Py-IR) and $\mathrm{NH}_{3}$ temperature programmed desorption ( $\left.\mathrm{NH}_{3}-\mathrm{TPD}\right)$. The Py-IR measurement were also performed on the Nicolet 6700 spectrometer device equipped with a diffuse reflectance attachment and an MCT detector. The $\mathrm{SO}_{4}{ }^{2-} / \mathrm{TiO}_{2}$ powders were placed into an in-situ chamber and smoothed, which were preliminarily pretreated with $\mathrm{He}(30 \mathrm{~mL} / \mathrm{min})$ at $300{ }^{\circ} \mathrm{C}$ for $1 \mathrm{~h}$ and then cooled down to room temperature. Subsequently, gaseous pyridine was adsorbed on powders until the adsorption saturation. The physical absorption of pyridine was removed by $\mathrm{He}$ purge for $1 \mathrm{~h}$. Finally, the infrared spectrum in the region from $1650 \mathrm{~cm}-1$ to $1400 \mathrm{~cm}^{-1}$ was recorded. Moreover, $\mathrm{NH}_{3}$-TPD experiment was conducted on a TP-5000 equipment (Tianjin Xianquan Co., Ltd., China). Similarly, the $\mathrm{SO}_{4}{ }^{2-} / \mathrm{TiO}_{2}$ powders were in-situ pretreated in He atmosphere at $300{ }^{\circ} \mathrm{C}$ for $1 \mathrm{~h}$ before test. After being cooled down to room temperature, the in-situ chamber was injected by $5 \% \mathrm{NH}_{3} / \mathrm{He}$ gas till saturation of adsorption capacity. Followed by He purge for $1 \mathrm{~h}$, the $\mathrm{NH}_{3}$ TPD signal of $\mathrm{SO}_{4}{ }^{2-} / \mathrm{TiO}_{2}$ was recorded as a function of temperature from $40{ }^{\circ} \mathrm{C}$ to $580{ }^{\circ} \mathrm{C}$ at a heating rate of $5{ }^{\circ} \mathrm{C}$ $\min ^{-1}$.

The Lewis acid sites and $\operatorname{Br} \emptyset$ nsted acid sites ratio are calculated in the following equations. ${ }^{[19,20]}$

$$
X_{\text {Brønsted }}=\frac{I_{B}}{I_{B}+0.752 I_{L}} \times 100 \%
$$

$$
X_{\text {Lewis }}=\frac{I_{L}}{1.329 I_{B}+I_{L}} \times 100 \%
$$

where $I_{B}$ and $I_{L}$ are the integrated area of peaks at 1540 $\mathrm{cm}^{-1}$ and $1445 \mathrm{~cm}^{-1}$, respectively. $X_{B r \emptyset n s t e d}$ and $X_{\text {Lewis }}$ are the molar percentage of Lewis acid sites and BrØnsted acid sites, respectively.

The thermal stability of bio-oil was determined by thermogravimetric analysis (TGA, TGA8000, PerkinElmer, Waltham, MA, USA) in a $\mathrm{N}_{2}$ atmosphere from 20 to $600{ }^{\circ} \mathrm{C}$ with a heating rate of $10{ }^{\circ} \mathrm{C} / \mathrm{min}$. The molecular structures of Bio-oil were analysed by $13 \mathrm{C}$ nuclear magnetic resonance (13C NMR, Bruker AVANCE II 400M) in DMSO. The elemental analysis $(\mathrm{C}, \mathrm{H}, \mathrm{N}, \mathrm{S})$ of bio-oil was carried out at a vario EL cube elemental analyzer (Elementar). The $\mathrm{O}$ and inorganics elements were obtained by the subtraction of the sum of $\mathrm{C}, \mathrm{H}, \mathrm{N}$ and $\mathrm{S}$. Pyrolysis-gas chromatography/mass spectrometry (Py-GC/MS) system was employed to separate and identify the pyrolysis volatiles. For this purpose, a CDS5200-type pyrolyser was directly attached to a gas chromatography/mass spectrometry (Clarus SQ8, PerkinElmer). The analytical pyrolysis experiments were performed in trap mode and the pyrolysis vapors from the reactor were absorbed on an adsorbent cartridge at $45{ }^{\circ} \mathrm{C}$, then was followed by desorption of the pyrolysis vapors from the cartridge at a heating rate of $100{ }^{\circ} \mathrm{C} / \mathrm{min}$ to $400{ }^{\circ} \mathrm{C}$. And the pyrolysis vapors were directly sent to $\mathrm{GC} / \mathrm{MS}$ for analysis and an Elite-5MS capillary column $(30 \mathrm{~m} \times 0.25 \mathrm{~mm} \times 0.25 \mu \mathrm{m}$ film thickness) was used for GC separation. Helium $(99.999 \%)$ was used as the carrier gas with a constant flow of $1.0 \mathrm{~mL} / \mathrm{min}$. Before the chromatographic separation, the temperature of the chromatographic column was progressively increased as follows: (i) $40{ }^{\circ} \mathrm{C}$ for $2 \mathrm{~min}$; (ii) from 40 to $295{ }^{\circ} \mathrm{C}$ at a rate of $8{ }^{\circ} \mathrm{C} / \mathrm{min}$; (iii) the capillary column was maintained at $295^{\circ} \mathrm{C}$ for about $40 \mathrm{~min}$. The GC inlet was $300{ }^{\circ} \mathrm{C}$ and a split ration of $50: 1$ was used. Mass spectra were recorded under electron ionization $(70 \mathrm{eV})$ with the $\mathrm{m} / \mathrm{z}$ range: $35-550$ au. Peak identification was carried out with the NIST mass spectral library and literatures.

An Optimol SRV-III oscillating friction and wear tester was used to evaluate tribological properties of the lubricants under lubrication conditions based on ASTM D 6425 protocol. The detailed test process refers to our previous publications. ${ }^{[9,21]}$ During the test, the upper steel ball (52100 bearing steel, diameter $10 \mathrm{~mm}$, surface roughness (Ra) 20 $\mathrm{nm})$ slides under reciprocating motion against a stationary steel disc (100CR6 ESU hardened, Ø24 mm×7.9 mm, and surface roughness (Ra) $120 \mathrm{~nm}$ ). All tests were conducted under the load of $150 \mathrm{~N}$ (2.5 GPa Maxium Hertzian pressure) at room temperature $\left(25^{\circ} \mathrm{C}\right)$, a sliding frequency of $50 \mathrm{~Hz}$, and an amplitude of $1 \mathrm{~mm}$. After the tests the wear volumes of the lower discs and wear diameter of the balls were determined using an optical profiling system (Zygo 7300). Three duplicate friction and wear tests were carried out to minimize the experimental error. 


\section{Results and discussion}

Compared with traditional liquid acid catalyst, sulfated solid superacid $\left(\mathrm{SO}_{4}^{2-} / \mathrm{TiO}_{2}\right)$ has obivious advantages of high catalytic-activity, rapid separation and easy recycling. ${ }^{[22,23]}$ We synthesized the $\mathrm{SO}_{4}^{2-} / \mathrm{TiO}_{2}$ catalyst for the bio-oil production from lignin. The physicochemical properties of the catalyst are compiled in Fig. $1 . \mathrm{SO}_{4}^{2-} / \mathrm{TiO}_{2}$ catalyst has the five distinct characteristic peaks at $2 \theta=25.36^{\circ}, 37.84^{\circ}$, $48.10^{\circ}, 53.94^{\circ}, 55.15^{\circ}$ in the X-ray diffraction (XRD) pattern of Fig. 1(a), which are consistent with the characteristic peaks of anatase $\mathrm{TiO}_{2}$. The bidentate coordination of sulfate groups to $\mathrm{Ti}$ cations of the support was demonstrated via the several peaks in the region of $1300-900 \mathrm{~cm}^{-1}$ in Fig. 1(b). ${ }^{[20]}$ Some typical peaks were also observed at 1135, 1092 and $1047 \mathrm{~cm}^{-1}$ corresponding to the vibration of $\mathrm{S}=\mathrm{O}$ and $\mathrm{S}-\mathrm{O}$ bond, due to the existence of sulfate group.

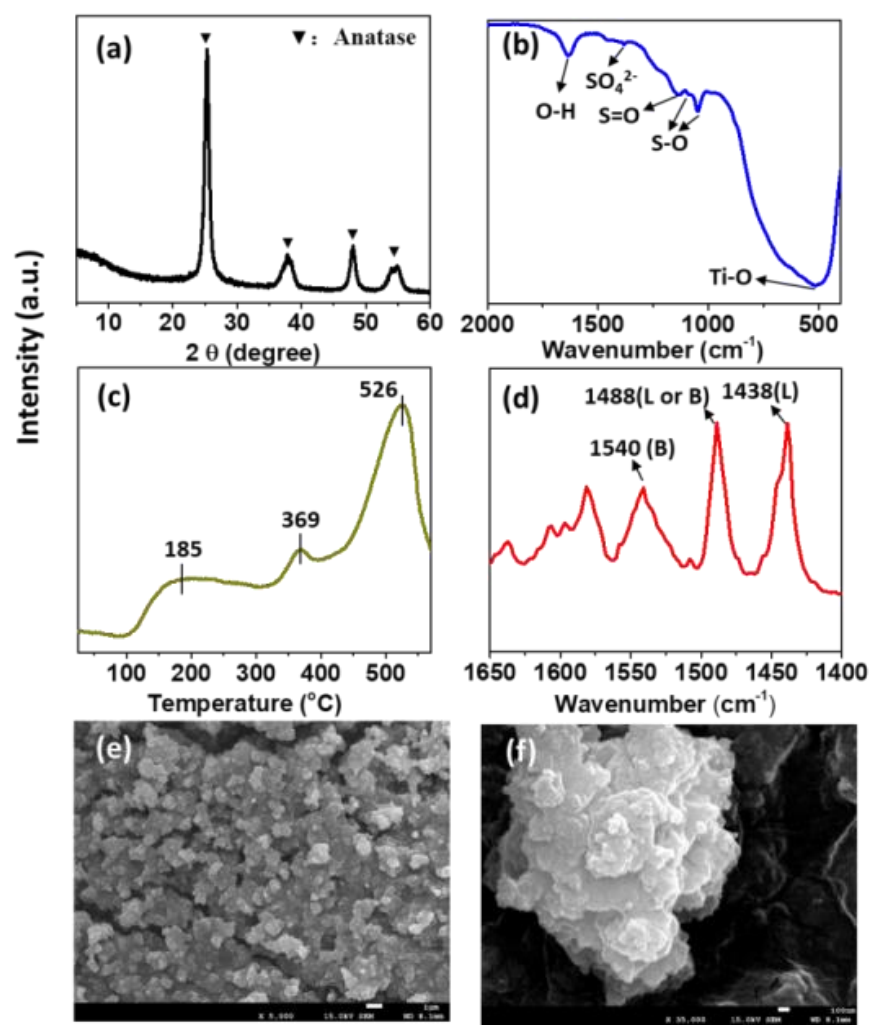

Fig. 1 Characterization of $\mathrm{SO}_{4}{ }^{2-} / \mathrm{TiO}_{2}$ (a) XRD, (b) FT-IR, (c) $\mathrm{NH}_{3}$ TPD, (d) Pyridine IR, (e) and (f) SEM image.

The $\mathrm{NH}_{3}$-TPD curve in Fig. 1(c) can be divided into three temperature regions of below $200{ }^{\circ} \mathrm{C}, 200 \sim 450{ }^{\circ} \mathrm{C}$ and above $450{ }^{\circ} \mathrm{C}$, which are ascribed to the adsorption of $\mathrm{NH}_{3}$ onto weak acid sites, medium acid sites and strong acid sites, respectively. ${ }^{[20]}$ Three $\mathrm{NH}_{3}$ desorption peaks at 185, 369 and $526{ }^{\circ} \mathrm{C}$ can be observed in $\mathrm{SO}_{4}{ }^{2-} / \mathrm{TiO}_{2}$ catalyst. The strong acid is relatively more than weak and medium acid. Moreover, the pyridine IR spectrum was used to study the acid type of $\mathrm{SO}_{4}^{2-} / \mathrm{TiO}_{2}$ in Fig.1 (d). The obvious peaks at 1540 and $1438 \mathrm{~cm}^{-1}$ are ascribed to the adsorption of pyridine onto Brønsted acid sites and Lewis acid sites. The ratio of Brønsted acid sites is $58.3 \%$, which is higher than that of
Lewis acid sites (41.7\%). The calculated equations are provided in Equation (4) \& (5). ${ }^{[19]}$ Nitrogen adsorptiondesorption isotherms of $\mathrm{SO}_{4}^{2-} / \mathrm{TiO}_{2}$ exhibits a type IV isotherm characteristic, indicating the presence of mesoporous structure, as shown in ESI Fig. S1. The surface area and pore volume of $\mathrm{SO}_{4}^{2-} / \mathrm{TiO}_{2}$ are $65.6 \mathrm{~m}^{2} / \mathrm{g}$ and 0.33 $\mathrm{cm}^{3} / \mathrm{g}$ respectively in ESI Table $\mathrm{S} 1$. Scanning electron microscopy of $\mathrm{SO}_{4}{ }^{2-} / \mathrm{TiO}_{2}$ shows small spherical particles with a diameter of about $30 \mathrm{~nm}$ in Fig. 1(e)-(f). The surface of the catalyst becomes rough, which may provide more acid and thereby improve the catalytic activity of $\mathrm{SO}_{4}^{2-} / \mathrm{TiO}_{2}$.

Table 1 Mass yield of element of bio-oil.

\begin{tabular}{|c|c|c|c|c|}
\hline \multicolumn{2}{|c|}{ Parameter } & Bio-1 & Bio-2 & Bio-3 \\
\hline \multirow{4}{*}{$\begin{array}{c}\text { Mass Yield } \\
(\%)\end{array}$} & Liquid & 81.50 & 79.75 & 85.25 \\
\hline & Lubricating oil & 12.50 & 11.85 & 13.50 \\
\hline & Char & 9.50 & 11.75 & 11.15 \\
\hline & Gas & 9.00 & 8.50 & 3.60 \\
\hline \multirow{5}{*}{$\begin{array}{c}\text { Element } \\
(\mathrm{wt} \%)\end{array}$} & $\mathrm{C}$ & 40.61 & 46.2 & 45.99 \\
\hline & $\mathrm{H}$ & 6.96 & 6.37 & 6.24 \\
\hline & $\mathrm{N}$ & 0.92 & 0.69 & 0.80 \\
\hline & $\mathrm{S}$ & 0.10 & 0.07 & 0.32 \\
\hline & $\mathrm{O}$ and Inorganics & 51.41 & 46.67 & 46.65 \\
\hline
\end{tabular}

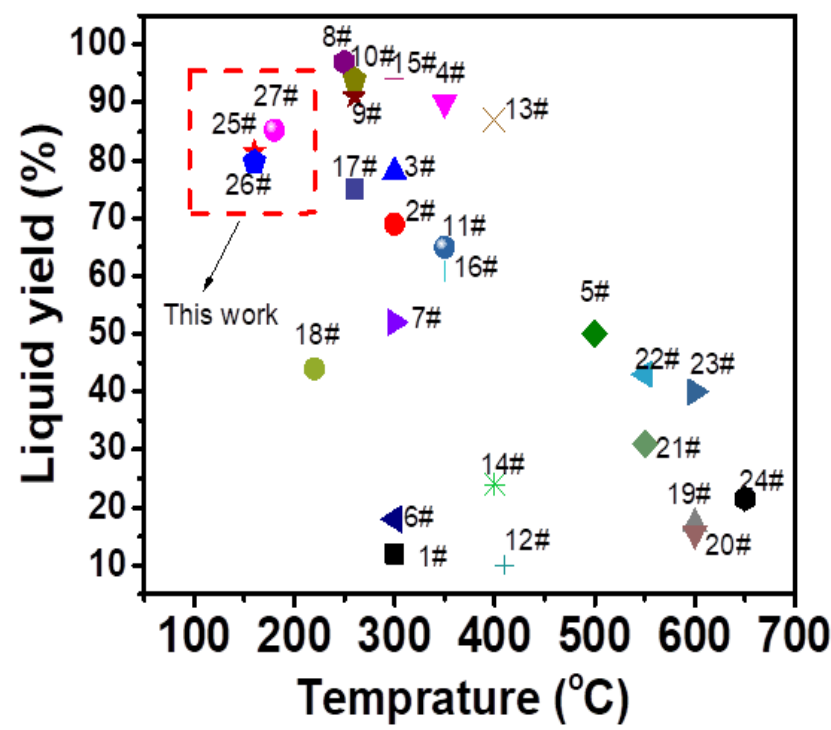

Fig. 2 Comparison of liquid yield between this work and literature results (1\# Alcell lignin; ${ }^{[24]}$ 2\# Kraft lignin; ${ }^{[25]} 3$ \# Soda lignin; ${ }^{[26]}$ 4\# Kraft lignin; ${ }^{[27]}$ 5\# Alkali lignin; ${ }^{[28]}$ 6\# Organosolv lignin; ${ }^{[29]}$ 7\# Organosolv lignin; ${ }^{[30]} 8 \#$ Pine lignin;[31] 9\# Alkali lignin; ${ }^{[32]}$ 10\# Organosolv lignin; ${ }^{[33]} 11 \#$ Wheat straw soda lignin; ${ }^{[34]}$ 12\# Allcell lignin; ${ }^{[35]} 13 \#$ Alcell and Pyrolytic lignin; ${ }^{[36]} 14 \#$ Organosolv lignin; ${ }^{[37]}$ 15\# Organosolv lignin; ${ }^{[38]}$ 16\# Kraft lignin; ${ }^{[39]} 17 \#$ Organosolv Lignin; ${ }^{[40]} 18 \#$ Kraft

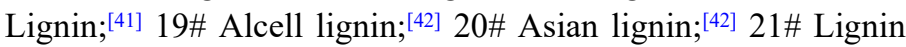
(byproduct of fermenting); ;43] 22\# Alcell lignin; ${ }^{[44]}$ 23\# Pyrolytic lignin from water; ${ }^{[4]} 24 \#$ Alkali lignin; ${ }^{[46]} 25 \#, 26 \#, 27 \#$ This work).

The mass yield and elements of bio-oil are summarized in Table 1. The liquid and char yield were calculated as its 
liquid and mass divided by the mass of dry lignin loaded into the reactor in Equation (1) \& (2), respectively. The gas yield was calculated by the mass difference between dry lignin and char/liquid. The high liquid yield (79.75 85.25\%) is obtained at the mild conditions as compared with the reported maximum liquid yield at the different temperature testing conditions, as shown in Fig. 2. For more details refer to Table $\mathrm{S} 1$ in the ESI. The higher temperature and less catalyst can lead to the high liquid mass yield and less char production. To investigate the possibility of bio-oil without glycerol solvent as the lubricant, we mixed the liquid from lignin with ethyl acetate/water (1:1 volume ratio) solution and get the bio-oil organic liquid from the ethyl acetate phase after the evaporation of solvent via a rotary evaporator at $45{ }^{\circ} \mathrm{C}$. The lubricating oil yield extracted from ethyl acetate is from 11.85 to $13.50 \%$ from Equation (3). The organic liquid from ethyl acetate will be used as the base oil to investigate lubrication properties and the structure characterization.

The carbon, hydrogen, nitrogen and sulfur elements of their bio-oil don't change a lot at the different temperature and catalyst ratio. Nitrogen and sulfur hetero-elements are beneficial for the robust protective surface film formation and thereby enhancing the lubrication properties. ${ }^{[47,48]} \mathrm{We}$ characterized the structure of bio-oil as depicted in ESI Fig. S2 8. Different functional group ratio and major component ratio of bio-oil are summarized in Fig. 3. On the basis of the chemical shift map of current compounds in bio-oil, ${ }^{[49]}$ the most aromatic $\mathrm{C}-\mathrm{O}$ bonds, aromatic $\mathrm{C}-\mathrm{H}$ bonds and aliphatic $\mathrm{C}-\mathrm{O}$ bonds are located in the chemical shift change of 142.0 $166.5 \mathrm{ppm}, 95.8-125.0 \mathrm{ppm}$ and 60.8-95.8 ppm, respectively. The oxygen content in bio-oil is very important to determine the properties of bio-oil for the application. We calculated the ratio of the two kinds of $\mathrm{C}-\mathrm{O}$ functional groups in bio-oil in Fig. 3(a). The aliphatic $\mathrm{C}-\mathrm{O}$ group in bio-oil is in following order: Bio-1> Bio-3> Bio-2. However, there is the opposite order for the aromatic $\mathrm{C}-\mathrm{O}$ group in bio-oil (Bio-2 $>$ Bio$3>$ Bio-1). We calculated the sum of the major acid, alcohol, ester and ether components in Fig.3 (b), which are larger than $1 \%$ in GC-MS analysis. The total acid in bio-oil is in following order: Bio-1>Bio-3> Bio-2. The alcohol relationship among the three kinds of bio-oil is Bio-3> Bio$2>$ Bo-1. There is the opposite order for the ester/ether components among the bio-oil, which may be attributed to the ester reaction among the acid/alcohol and alcohol/alcohol component.

Thermal property of bio-oils has been investigated, which is one of the most important properties for lubricant. Three bio-oils show no melting and crystallization behavior during the heating and cooling process, in ESI Fig. S9, which means that the bio-oil has the possibility to be used the liquid lubricant from -50 to $150{ }^{\circ} \mathrm{C}$. Bio-oil is thermally stable within the low temperature range and shows a single degradation peak centered at $245 \sim 250{ }^{\circ} \mathrm{C}$ in the derivative thermogravimetric (DTG) curves (in ESI Fig. S10).

The lubricating properties of bio-oil were evaluated using an optimol SRV-III oscillation friction and wear tester at room temperature. The results are summarized in Fig. 4. The friction coefficient (COF), disc wear volume and ball wear diameter are the key performance index to value the lubrication properties. The friction coefficient refers to the ratio of the friction force between two relative motive surfaces and the vertical force acting on one of the surfaces. The larger COF will imply the high friction forces generated during the relative motion, which will lead to the high energy consumption or failure in the system. ${ }^{[50]}$ The ball wear diameter and disc wear volume refer to the circular diameter change of the steel ball and steel disc wear loss after the friction test, respectively. Both of them reflect the anti-wear properties of lubricants. The lower ball wear diameter and disc wear volume indicate the better anti-wear properties, and vice versa. ${ }^{[5]}$ To value the possibility of the bio-oil as the commercial lubricant base oil, polyethylene glycol 200 (PEG 200) was tested as the control sample. PEG has been successfully used in various applications, such as lubricants

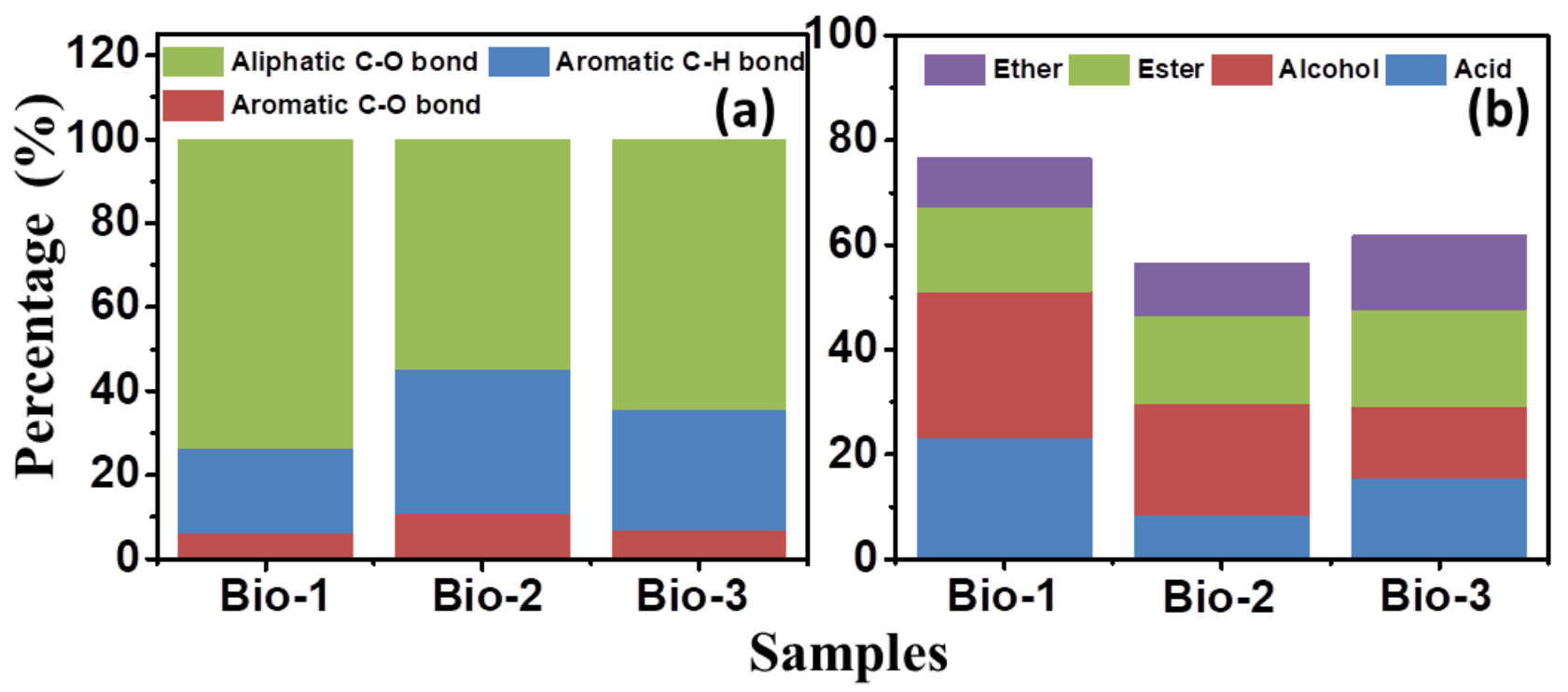

Fig. 3 (a) Different functional group ratio of bio-oil; (b) major component ratio of bio-oil. 
and cosmetics. Apparently, the sharp jump of friction coefficient of Bio-1 indicates unstable friction coefficient, Fig. 4(a). Bio-2, Bio-3 and PEG200 have the stable COF in Fig. 4(b)-(d). The average COF of bio-oil is noticeably lower than that of PEG200. Specifically, the COF of Bio-2 is $61.8 \%$ of that of PEG200. The anti-wear properties lubricated by bio-oil and PEG200 of Fig. 4 (e)-(f) is in following order: $\mathrm{W}_{\text {PEG200 }}>\mathrm{W}_{\text {Bio-1 }}>\mathrm{W}_{\text {Bio-3 }}>\mathrm{W}_{\text {Bio-2 }}$.
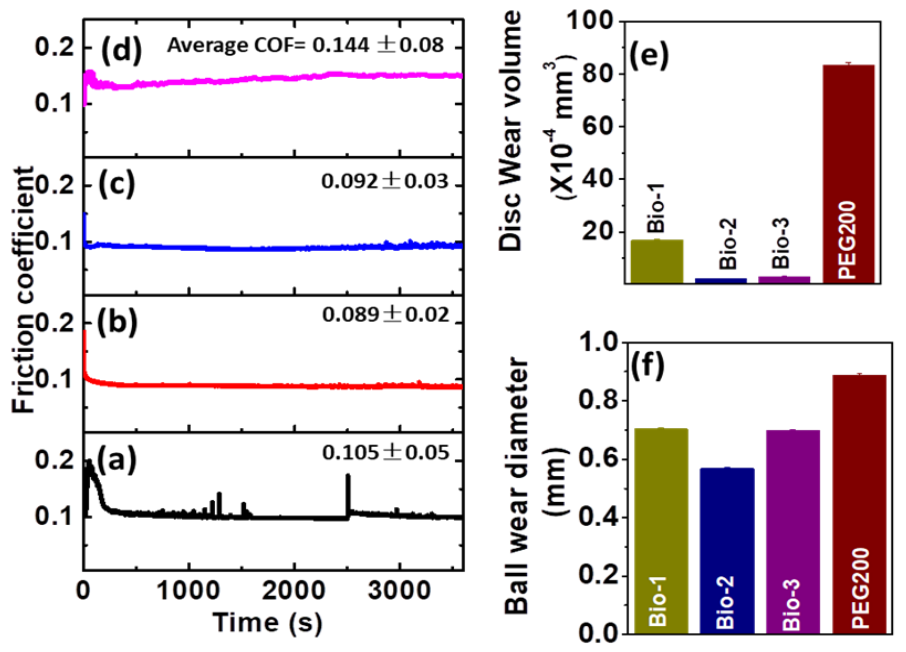

Fig. 4 (a-d) Friction coefficient, (e) disc wear volume and (f) ball wear diameter lubricated by bio-oil and PEG200. Load: 2.5 $\mathrm{GPa}$, testing duration: $1 \mathrm{~h}$, room temperature.(a): Bio-1, (b): Bio-2, (c): Bio-3, (d): PEG200.

The steel balls and steel disc wear three-dimensional microscopic are provided in Fig. 5 (a)-(d) \& (a')-(d'). All of the bio-oil samples showed a marked decrease in wear volume, in Fig. 4(e). Specifically, the wear volume of the steel disc lubricated by Bio- 2 is only $2.4 \%$ of the one lubricated by PEG200. Overall, the bio-oil has the better lubrication properties than the commercial base oil PEG200. Recall the structure of bio-oil results that the more ether/ester and less acid at the Bio-2 as compared with other bio-oil, the anti-wear properties of bio-oil is closely correlated and could be attributed to the positive effect of the more ether/ester and less acid in the system. From the GC-MS result, we can see there is much acetic acid in the bio-oil, which is volatile acid and lead to the instability of the bio-oil during the friction process. It is difficult to separate the chemicals in bio-oil even though we have used extraction method to get the biooil organic liquid. The acetic acid content in bio-oil is in following order: Bio-1 $>$ Bio-3 $>$ Bio-2, in ESI Fig. S6 8. The more acetic acid will lead to worse lubrication properties. The esterification between glycerol and acetic acid would occur in the presence of the sulfated solid superacid catalyst in Fig. 6. The more glycerol 1-acetate content in Bio-2 indicates that the esterification reaction could consume more acetic acid, which is beneficial for the stability of the bio-oil and lubrication properties. In this system, it is shown that glycerol could be used as the solvent in the depolymerization reaction and reactant in the upgrading reaction.

\section{Conclusions}

To sum up, we have proposed the strategy to produce a biooil using lignin as the feedback under glycerol/methanol based catalytic system via sulfated solid superacid catalyst. It is demonstrated that bio-oil are a promising class of the highperformance lubricant. Significant reductions in both COF $(38.2 \%)$ and wear $(97.6 \%)$ were observed with bio-oil as compared with commercial lubricant oil (polyethylene glycol 200). The more aromatic C-O group, ether/ester, and less acetic acid in bio-oil have the positive contribution to the lubrication properties. This work will open up a new application of using lignin as advanced lubricants. Meanwhile, the diversity of lignin from the varied plants and different fractionation processes will lead to the different molecular structure of bio-oil, which will result in a plenty of work to design the bio-oil from lignin towards excellent lubrication properties. The utilization of machine learning methods will speed up the screen process of the bio-oil from lignin for industrial application in future.
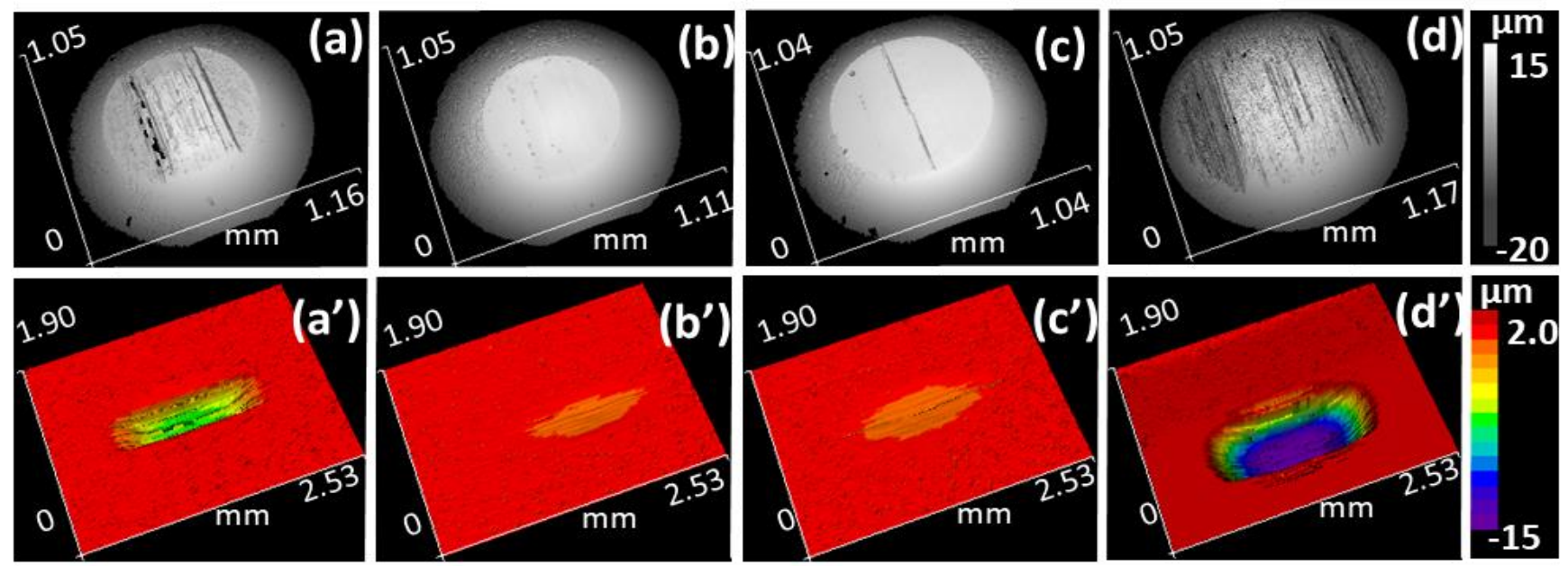

Fig. 5 3D surface profile of the wear tracks on disc (a-d) and ball (a'-d') by using bio-oil and PEG200. Load: 2.5 GPa, testing duration: 1 h, room temperature. (a \& a'): Bio-1, (b \& b'): Bio-2, (c \& c'): Bio-3, (d \& d'): PEG200. 


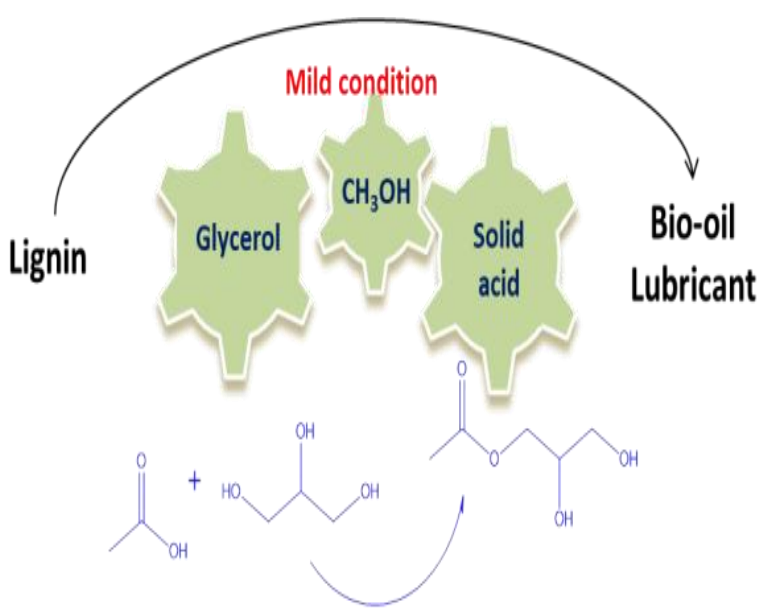

Fig. 6 Schematic strategy for the bio-oil form lignin.

\section{Acknowledgements}

Acknowledgement is made to the financial support from Swedish Kempe Scholarship Project (JCK-1903.1), the Swedish Research Council for Environment, Agricultural Sciences, and Spatial Planning (Formas, 2019-01162) and National Natural Science Foundation of China (21774059, 21808102).

\section{Conflict of Interest}

There is no conflict of interest.

\section{Supporting Information}

Applicable.

\section{Reference}

[1] G. Kumar, S. Shobana, W.-H. Chen, Q.-V. Bach, S.-H. Kim, A. E. Atabani, J.-S. Chang, Green Chem., 2017,19, 44-67, doi: 10.1039/c6gc01937d.

[2] A. R. K. Gollakota, H. D. Kawale, N. Kishore, S. Gu, Renew. Sust. Energy Rev., 2018, 98, 515-517, doi: 10.1016/j.rser.2018.08.047.

[3] K. F. Tzanetis, J. A. Posada, A. Ramirez, Renew. Energy, 2017, 113, 1388-1398. doi: 10.1016/j.renene.2017.06.104.

[4] P. Basu, Biomass gasification, pyrolysis and torrefaction: practical design and theory, 2013, pp, 375-404. doi: 10.1016/B978-0-12-396488-5.00011-3.

[5] S. Anouti, G. Haarlemmer, M. Déniel, A. Roubaud, Energ. Fuel., 2016, 30, 398-406. doi: 10.1021/acs.energyfuels.5b02264. [6] A. Oasmaa, D. C. Elliott, J. Korhonen, Energ. Fuel., 2010, 24, 6548-6554. doi: doi.org/10.1021/ef100935r.

[7] Y. Zhou, J. Qu, ACS Appl. Mater. Interfaces, 2017,9, 3209 3222, doi: 10.1021/acsami.6b12489.

[8] L. Mu, Y. Shi, X. Guo, T. Ji, L. Chen, R. Yuan, L. Brisbin, H. Wang, J. Zhu, RSC Adv., 2015, 5, 66067-66072, doi: 10.1039/c5ra11093a.

[9] L. Mu, Y. Shi, X. Guo, W. Zhuang, L. Chen, T. Ji, J. Hua, H. Wang, J. Zhu, J. Colloid Interf. Sci., 2017, 498, 47-54. doi: 10.1016/j.jcis.2017.03.044.
[10] L. Mu, Y. Shi, J. Hua, W. Zhuang, J. Zhu, J. Phys. Chem. B, 2017, 121, 5669-5678, doi: 10.1021/acs.jpcb.7b03194.

[11] Y. Liao, S.-F. Koelewijn, G. Van den Bossche, J. Van Aelst, S. Van den Bosch, T. Renders, K. Navare, T. Nicolaï, K. Van Aelst, M. Maesen, H. Matsushima, J. M. Thevelein, K. Van Acker, B. Lagrain, D. Verboekend, B. F. Sels, Science, 2020, 367, 1385, doi: 10.1126/science.aau1567.

[12] Z.-K. Wang, S. Hong, J.-1. Wen, C.-y. Ma, L. Tang, H. Jiang, J.-J. Chen, S. Li, X.-J. Shen, T.-Q. Yuan, ACS Sustain. Chem. Eng., 2020, 8, 1050-1057, doi: 10.1021/acssuschemeng.9b05846.

[13] O. E. Ebikade, N. Samulewicz, S. Xuan, J. D. Sheehan, C. Wu, D. G. Vlachos, Green Chem., 2020, 22, 7435-7447, doi: 10.1039/d0gc02781b.

[14] W.-J. Liu, H. Jiang, H.-Q. Yu, Green Chem., 2015, 17, 4888-4907, doi: 10.1039/c5gc01054c.

[15] B. M. Upton, A. M. Kasko, Chem. Rev., 2016, 116, 2275 2306, doi: 10.1021/acs.chemrev.5b00345.

[16] C. S. Lancefield, O. S. Ojo, F. Tran, N. J. Westwood, Angew. Chem. Int. Ed., 2015, 54, 258-262, doi: 10.1002/anie.201409408.

[17] T. Ren, W. Qi, R. Su, Z. He, Chemcatchem, 2019, 11, 639654. doi: 10.1002/cctc.201801428.

[18] C. W. Lahive, P. J. Deuss, C. S. Lancefield, Z. Sun, D. B. Cordes, C. M. Young, F. Tran, A. M. Z. Slawin, J. G. de Vries, P. C. J. Kamer, N. J. Westwood, K. Barta, J. Am. Chem. Soc., 2016,138, 8900-8911, doi: 10.1021/jacs.6b04144.

[19] C. A. Emeis, J. Catal., 1993, 141, 347-354, doi: 10.1006/jcat.1993.1145.

[20] L. Li, H. Yue, T. Ji, W. Li, X. Zhao, L. Wang, J. She, X. Gu, X. Li, Appl. Catal. A, 2019, 574, 25-32, doi: 10.1016/j.apcata.2019.01.025.

[21] L. Mu, D. Cao, W. Zhuang, Q. Yu, M. Cai, Y. Shi, Adv. Mater. Interfaces, 2020, 7, 1902194, doi: 10.1002/admi.201902194.

[22] F. Su, Y. Guo, Green Chem., 2014, 16, 2934-2957, doi: 10.1039/C3GC42333F.

[23] B. M. Reddy, M. K. Patil, Chem. Rev., 2009, 109, $2185-$ 2208, doi: $10.1021 / \mathrm{cr} 900008 \mathrm{~m}$.

[24] R. J. A. Gosselink, W. Teunissen, J. E. G. van Dam, E. de Jong, G. Gellerstedt, E. L. Scott, J. P. M. Sanders, Bioresour. Technol., 2012, 106, 173-177, doi: 10.1016/j.biortech.2011.11.121.

[25] H.-s. Lee, J. Jae, J.-M. Ha, D. J. Suh, Bioresour. Technol., 2016, 203, 142-149, doi: 10.1016/j.biortech.2015.12.022.

[26] X. Huang, T. I. Korányi, M. D. Boot, E. J. M. Hensen, ChemSusChem, 2014,7, 2276-2288, doi: 10.1002/cssc.201402094.

[27] A. Riaz, C. S. Kim, Y. Kim, J. Kim, Fuel, 2016, 172, 238247. doi: 10.1016/j.fuel.2015.12.051.

[28] A. M. Numan-Al-Mobin, K. Voeller, H. Bilek, E. Kozliak, A. Kubatova, D. Raynie, D. Dixon, A. Smirnova, Energy Fuels, 2016, 30, 2137-2143, doi: 10.1021/acs.energyfuels.5b02136. 
[29] X. Erdocia, R. Prado, M. Angeles Corcuera, J. Labidi, Biomass Bioenergy, 2014, 66, 379-386. doi: 10.1016/j.biombioe.2014.03.021.

[30] V. M. Roberts, V. Stein, T. Reiner, A. Lemonidou, X. Li, J. A. Lercher, Chem. Eur. J., 2011, 17, 5939-5948. doi: 10.1002/chem.201002438.

[31] J. Long, Q. Zhang, T. Wang, X. Zhang, Y. Xu, L. Ma, Bioresour. Technol., 2014, 154, 10-17, doi: 10.1016/j.biortech.2013.12.020.

[32] R. Shu, J. Long, Z. Yuan, Q. Zhang, T. Wang, C. Wang, L. Ma, Bioresour. Technol., 2015, 179, 84-90, doi: 10.1016/j.biortech.2014.12.021.

[33] J. Long, Y. Xu, T. Wang, Z. Yuan, R. Shu, Q. Zhang, L. Ma, Appl. Energy, 2015, 141, 70-79, doi: 10.1016/j.apenergy.2014.12.025.

[34] B. Joffres, C. Lorentz, M. Vidalie, D. Laurenti, A. A. Quoineaud, N. Charon, A. Daudin, A. Quignard, C. Geantet, Appl. Catal. B, 2014, 145, 167-176, doi: 10.1016/j.apcatb.2013.01.039.

[35] R. W. Thring, J. Breau, Fuel, 1996, 75, 795-800, doi: 10.1016/0016-2361(96)00036-1.

[36] A. Kloekhorst, H. J. Heeres, ACS Sustain. Chem. Eng., 2015, 3, 1905-1914, doi: 10.1021/acssuschemeng.5b00041.

[37] M. Osada, T. Sato, M. Watanabe, T. Adschiri, K. Arai, Energy Fuels, 2004, 18, 327-333. doi: 10.1021/ef034026y.

[38] S. Cheng, Z. Yuan, M. Leitch, M. Anderson, C. C. Xu, Ind. Crops Prod., 2013, 44, 315-322. doi: 10.1016/j.indcrop.2012.10.033

[39] J.-Y. Kim, J. Park, H. Hwang, J. K. Kim, I. K. Song, J. W. Choi, J. Anal. Appl. Pyrolysis, 2015, 113, 99-106. doi: 10.1016/j.jaap.2014.11.011.

[40] G. Warner, T. S. Hansen, A. Riisager, E. S. Beach, K. Barta, P. T. Anastas, Bioresour. Technol., 2014, 161, 78-83. doi: 10.1016/j.biortech.2014.02.092.

[41] S. K. Singh, J. D. Ekhe, RSC Adv., 2014, 4, 53220-53228. doi: 10.1039/C4RA10240A.

[42] Y. Ye, J. Fan, J. Chang, J. Anal. Appl. Pyrolysis, 2012, 94, 190-195. doi: 10.1016/j.jaap.2011.12.005.

[43] T. N. Trinh, P. A. Jensen, Z. Sárossy, K. Dam-Johansen, N. O. Knudsen, H. R. Sørensen, H. Egsgaard, Energ. Fuel., 2013, 27, 3802-3810, doi: 10.1021/ef400527k.

[44] R. W. Thring, S. P. R. Katikaneni, N. N. Bakhshi, Fuel Process. Technol., 2000, 62, 17-30, doi: 10.1016/S03783820(99)00061-2.

[45] Y. Zhao, L. Deng, B. Liao, Y. Fu, Q.-X. Guo, Energy Fuels, 2010,24, 5735-5740, doi: 10.1021/ef100896q.

[46] X. Li, L. Su, Y. Wang, Y. Yu, C. Wang, X. Li, Z. Wang, Front. Environ. Sci. Eng., 2012,6, 295-303, doi: 10.1007/s11783-012-0410-2.

[47] X. Fu, L. Sun, X. Zhou, Z. Li, T. Ren, Tribol. Lett., 2015, 60, doi: 10.1007/s11249-015-0596-0.

[48] J. M. Martin, C. Grossiord, T. Le Mogne, J. Igarashi, Tribol. Int., 2000,33, 453-459, doi: 10.1016/S0301679X(00)00073-6.
[49] H. Ben, A. J. Ragauskas, Energ. Fuel., 2011,25, 2322-2332, doi: 10.1021/ef2001162.

[50] P. J. Blau, Tribol. Int., 2001,34, 585-591, doi: 10.1016/S0301-679X(01)00050-0.

[51] E. P. Georgiou, L. M. Lopes, M. De Bilde, D. Drees, Wear, 2020, 203414, 458-459, doi: 10.1016/j.wear.2020.203414.

\section{Author information}

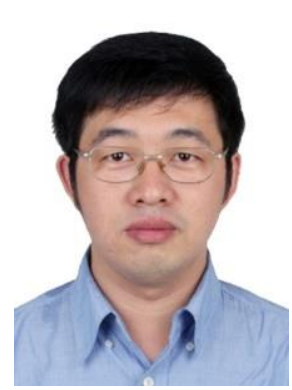

Liwen $\mathbf{M u}$ is a researcher in Division of Machine Elements, Luleå University of Technology, Sweden. He received his Ph.D. from Nanjing Tech University, China in 2012. He has published more than 80 papers on international peer reviewed journals. One of his research interests is developing multi-functional composites based on biomass such as green lubricating materials.

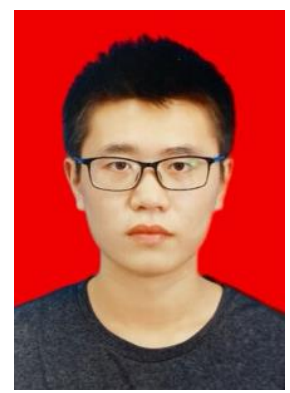

Yuguo Dong will complete his bachelor's degree in the school of chemical engineering of Nanjing Forestry University in 2021. After that, he will continue to pursue his doctorate in the school of chemical engineering of Nanjing Forestry University. His areas of interest include depolymerization of lignin to produce high value-added chemicals. He has published 7 research articles in various academic journals, and applied for 4 Chinese invention patents and 10 Chinese utility model patents.

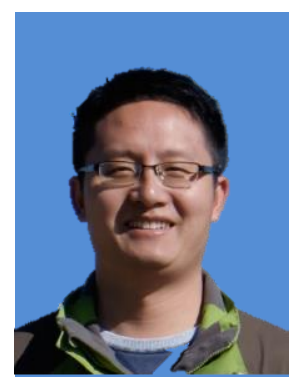

Licheng Li completed his Ph. D degree from State Key Laboratory of MaterialsOriented Chemical Engineering, Nanjing Tech University, Nanjing in 2013. He has been engaged in development of the novel heterogeneous catalyst and related fundamental researches. Currently he is an associated professor in the college of chemical engineering of Nanjing Forestry University.

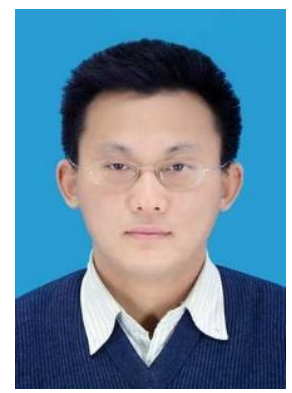

Xiaoli $\boldsymbol{G u}$ completed his Ph. D degree from Department of Chemical Engineering, Nanjing Tech University, Nanjing in 2005. His research area of interest is biomass catalytic conversion and lignin modified material. He has published more than 40 research articles in various peer reviewed journals. 
Currently he is a research professor at Nanjing Forestry University.

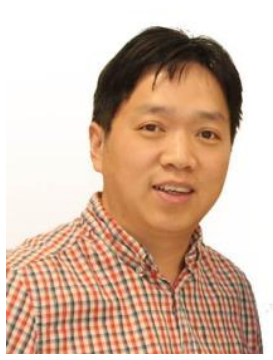

Yijun Shi is now Professor in Division of Machine Elements, Luleå University of Technology, Sweden. He received his Ph.D. from Nanjing Tech University, China in 2007. He has published more than 80 papers on international peer reviewed journals. One of his current research interests is developing and applying green lubricating materials based on bio-mass.
Publisher's Note: Engineered Science Publisher remains neutral with regard to jurisdictional claims in published maps and institutional affiliations. 